\title{
REVIEW
}

\section{Solutions to infection prevention and control challenges in developing countries, do they exist? An integrative review}

\author{
Vanessa L Sparke ${ }^{1}$, Jason Diau², David MacLaren ${ }^{3}$, Caryn West ${ }^{1}$ \\ ${ }^{1}$ Discipline of Nursing and Midwifery, James Cook University, Cairns Campus, \\ Queensland, Australia \\ ${ }^{2}$ Atoifi Adventist Hospital, Honiara, Solomon Islands \\ ${ }^{3}$ College of Medicine and Dentistry, James Cook University, Cairns Campus, \\ Queensland, Australia
}

10.3396/ijic.v16i1.007.20

\begin{abstract}
Implementing sustainable infection prevention and control (IP\&C) programs in developing countries is challenging. Many developing countries experience high burdens of disease and political instability. In addition, they are affected by geographical and climatic challenges, and have unique social, cultural and spiritual beliefs, all of which contribute to a higher prevalence of infections. The aim of this integrative review is to identify existing solutions to the challenges faced by developing countries when implementing IP\&C programs. An extensive literature review was conducted to explore improvements in infection control in rural hospitals in developing countries. Three electronic databases were searched for relevant articles written between 1980 and 2018, published in peer reviewed English language journals, and relating to hospitals, not community settings. The findings indicate that developing countries continue to face many challenges in implementing IP\&C programs. Limited success has been described with some IP\&C program components but it is clear that little original research on the topic exists. Notably scarce are studies on the influences that culture, religious and spiritual beliefs have on IP\&C program implementation. This review highlights opportunities for further research into healthcare workers perceptions of disease causation and infection transmission, and the role this plays in the effective implementation of an IP\&C program. By exploring these opportunities appropriate and culturally sensitive solutions may be identified, which can assist with the design and implementation of culturally relevant IP\&C programs in these settings.
\end{abstract}

Keywords: Infection control, professional practice, developing countries

\author{
Corresponding Author \\ Vanessa Sparke \\ Lecturer in Nursing, Discipline of Nursing and Midwifery \\ James Cook University, Cairns Campus \\ PO Box 6811, Cairns, 4870 \\ Queensland, Australia \\ E-mail:vanessa.sparke1@jcu.edu.au
}




\section{Background}

Infection preventionand control(IP\&C) internationally is important for patient safety and quality care, but is challenging in developing countries. The prevalence of healthcare associated infections (HCAl) is higher in developing countries than developed countries; ${ }^{1}$ however the lack of formalised surveillance and audit means the true statistics are not revealed, leading to the assumption that the reality is substantially worse than the limited documented evidence suggests. The impact an HCAl has on a patient, the patient's family, the community, the healthcare staff and the healthcare facility in a developing country is monumental and compounded by high burden of disease, lack of physical and financial resources, poor hospital infrastructure, poor staff salaries, geographical isolation, and extremes of climate.

Defined as a country with less than $\$ 1,230$ (US) gross national income per capita, "developing countries" is a term often used interchangeably with lower middle income (LMI), resource poor, and least developed country (LDC). ${ }^{2,3}$ These countries face severe structural impediments to sustainable development due largely to economic vulnerability. ${ }^{3}$ One of the associated effects is the higher prevalence of HCAI and high rates of mortality and morbidity due to communicable diseases. . $^{1,4,5}$

In developed countries, successful implementation of evidenced-based infection control programs is driven by many factors including patient stay data, publicly reported HCAI rates, media attention, and litigation potential. ${ }^{6}$ Generic components include hand hygiene monitoring, isolation precaution practices, cleaning, sterilisation and disinfection, investigation and management of multi-drug resistant organisms, staff immunisation, surveillance and monitoring of invasive devices, all of which require physical resources, working healthcare infrastructure, financial support and educated IP\&C staff. In addition, local factors such as climate, geography, sociocultural, socioeconomic, political and demographic conditions, high costs of treatment, and antibiotic prescription habits make the implementation of IP\&C programs developed by highly resourced western countries almost impossible to implement in resource poor settings. ${ }^{6}$ Despite nearly
40 years of IP\&C evidence, practice and knowledge, health systems within developing countries continue to be challenged in the implementation of sustainable programs and therefore hindered by high burdens of disease and infections.

Given the influence that local factors have on the health systems ability to deliver IP\&C programs in developing countries, local adaptation is essential. With limited evidence in the literature ${ }^{8}$ that describes the social, religious, spiritual and cultural influences contributing to disease transmission in healthcare settings in developing countries, this review identifies a critical gap in the current body of knowledge. ${ }^{9}$

\section{Method}

A systematic search of online databases was undertaken using keywords and their synonyms, and was broadened to search keyword truncations $\left({ }^{*}\right)$. The PICO (problem, intervention, comparison, outcome) method was used to identify the following keywords: "infection control" AND improvement AND practice. ${ }^{10}$ The terms "infection control", improvement, practice, improve*, and practic*, were entered into CINAHL, Scopus, and Ovid Medline with a further search term AND "developing count*" added to limit the search to include literature pertaining to developing countries only. For literature that may have not been captured in the initial search, the synonym "limited resource" was used instead of "developing count", and "communicable disease control" was used instead of "infection control", however the latter search did not reveal anything further as literature tended to focus on issues around disease control in public health rather than in healthcare facilities. The search was limited to studies written in English and published later than 1979. The date was chosen as it follows the publication of the Study on the Efficacy of Nosocomial Infection Control (SENIC), the pioneering study which demonstrated the efficacy of hospital infection control programs. ${ }^{11}$

A total of 1763 titles and abstracts were identified during the initial search. Following preliminary screening using inclusion and exclusion criteria (Table I), 71 articles were retained, printed and read. Seven articles were further identified using ancestry 
searching of reference lists. After removing duplicates $(n=20), 58$ articles were read in-depth resulting in a further 42 articles being excluded. Of the 42 excluded articles, secondary screening revealed that while improvementsinIP\&Cwerediscussed briefly, solutions were either not offered, or at best, mentioned without any further explanation. A final number of 16 articles were synthesised and included in the present review (Table II). An adapted PRISMA flow chart was used to document the selection process during the review
(Figure I). ${ }^{12}$ The Critical Appraisal Skills Programme (CASP) evaluation checklist was applied to assess the quality of research articles, however as only four of the final 16 were research articles, with all other sources being reviews, opinion pieces, discussion articles, and commentaries, the CASP evaluation tool for systematic reviews was also utilised. ${ }^{13}$

Table I. Literature search inclusion and exclusion criteria Inclusion Criteria

Exclusion criteria

\begin{tabular}{ll}
\hline Published in English language & Published in languages other than English \\
\hline Published after 1979 & Published prior to 1980 \\
\hline Published in peer reviewed journals only & Focus on the Public Health domain \\
\hline Based in healthcare facilities & Based in tertiary hospitals in large cities \\
\hline & Disease specific focus \\
\hline & Ward specific focus
\end{tabular}




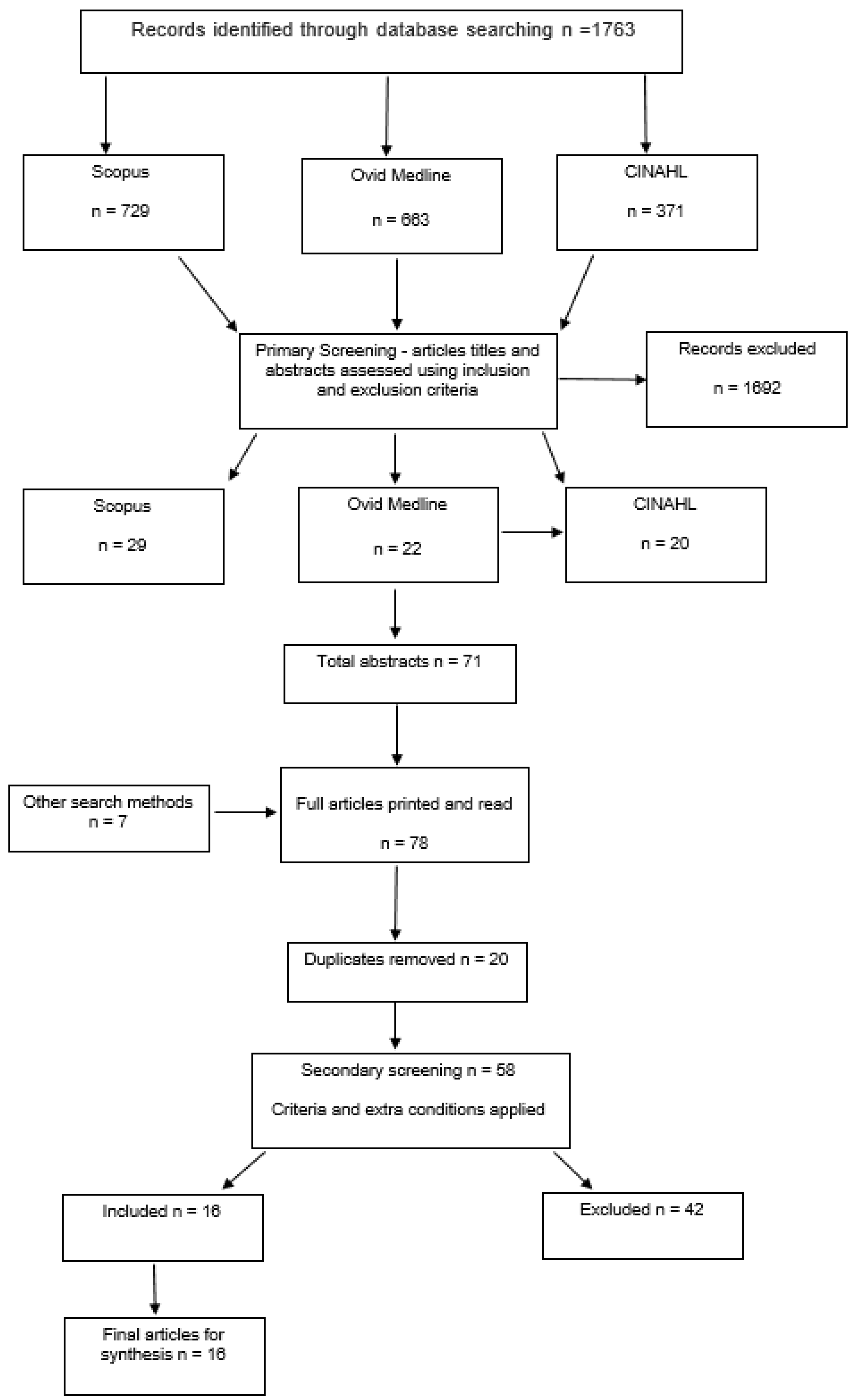

Figure 1. Modified PRISMA diagram indicating literature selection ${ }^{12}$ 


\section{Table II. Literature summary included in review}

\begin{tabular}{lllllll}
$\begin{array}{l}\text { Authors and } \\
\text { year }\end{array}$ & Title & $\begin{array}{l}\text { Country/ } \\
\text { Region }\end{array}$ & Type Aims & $\begin{array}{l}\text { Methodology } \\
\text { and design }\end{array}$ & Sample type Analysis & Key findings \\
\hline
\end{tabular}

\begin{tabular}{|c|c|c|c|c|}
\hline $\begin{array}{l}\text { Allegranzi, } \\
\text { Memish, } \\
\text { Donaldson, and } \\
\text { Pittet (2009) }\end{array}$ & $\begin{array}{l}\text { Religion and } \\
\text { culture: Potential } \\
\text { undercurrents } \\
\text { influencing hand } \\
\text { hygiene promotion in } \\
\text { healthcare }\end{array}$ & Global & Review & $\begin{array}{l}\text { Investigate } \\
\text { religio-cultural } \\
\text { factors that } \\
\text { may potentially } \\
\text { influence hand } \\
\text { hygiene promotion }\end{array}$ \\
\hline
\end{tabular}

An awareness of commonly held religious and cultural beliefs is vital when attempting to apply concept of modern medicine and good clinical practice.

\begin{tabular}{|c|c|c|c|c|}
\hline $\begin{array}{l}\text { Bardossy, } \\
\text { Zervos, and } \\
\text { Zervos (2016) }\end{array}$ & $\begin{array}{l}\text { Preventing Hospital- } \\
\text { acquired infections } \\
\text { in Low-income } \\
\text { and Middle- } \\
\text { income countries: } \\
\text { Impacts, gaps, and } \\
\text { opportunities }\end{array}$ & Global & Review & $\begin{array}{l}\text { Explore } \\
\text { approaches to } \\
\text { IP\&C program } \\
\text { implementation } \\
\text { in low and middle } \\
\text { income countries. }\end{array}$ \\
\hline
\end{tabular}

IP\&C programs in LMI countries should be simple, cost-effective and designed to suit local needs and circumstances, however more studies are recommended.

\begin{tabular}{|c|c|c|c|c|c|}
\hline Damani (2007) & $\begin{array}{l}\text { Simple measures } \\
\text { saves lives: An } \\
\text { approach to infection } \\
\text { control in countries } \\
\text { with limited } \\
\text { resources }\end{array}$ & Global & Opinion & $\begin{array}{l}\text { Discuss simple } \\
\text { measures to IP\&C } \\
\text { in countries with } \\
\text { limited resources. }\end{array}$ & $\begin{array}{l}\text { Application of } \\
\text { basic infection } \\
\text { control measures } \\
\text { is achievable } \\
\text { and affordable } \\
\text { in countries with } \\
\text { limited resources } \\
\text { and subsequently } \\
\text { save lives. }\end{array}$ \\
\hline $\begin{array}{l}\text { El-Nageh } \\
\text { (1995) }\end{array}$ & $\begin{array}{l}\text { How to combat } \\
\text { nosocomial } \\
\text { infections in } \\
\text { developing countries }\end{array}$ & Global & Opinion & $\begin{array}{l}\text { Combating } \\
\text { nosocomial } \\
\text { infections in } \\
\text { developing } \\
\text { countries } \\
\text { suggesting multi- } \\
\text { modal appraoches }\end{array}$ & $\begin{array}{l}\text { Tackling } \\
\text { nosocomial } \\
\text { infections requires } \\
\text { a surveillance } \\
\text { system, } \\
\text { provision of basic } \\
\text { infrastructure } \\
\text { and resources, } \\
\text { wound infection } \\
\text { management } \\
\text { and antibiotic } \\
\text { resistance testing. }\end{array}$ \\
\hline
\end{tabular}




\begin{tabular}{llll}
\hline $\begin{array}{l}\text { Huskins et al. } \\
\text { (1998) }\end{array}$ & $\begin{array}{l}\text { Hospital Infection } \\
\text { Prevention and } \\
\text { Control: A model for } \\
\text { improving the quality } \\
\text { of Hospital care in }\end{array}$ & $\begin{array}{l}\text { Original } \\
\text { article }\end{array}$ & $\begin{array}{l}\text { Describe the } \\
\text { design and } \\
\text { implementation of }\end{array}$ \\
& & $\begin{array}{l}\text { a demonstration } \\
\text { Income countries }\end{array}$ & project to reduce \\
& & the incidence \\
& of surgical site \\
& infections using \\
& the PDSA cycle
\end{tabular}

Because of the standardization of definitions, and surveillance methods, a CQI model can be applied in a coordinated approach across a number of hospitals to improve IP\&C

\begin{tabular}{|c|c|c|c|c|}
\hline $\begin{array}{l}\text { Jones, } \\
\text { Whitfield, } \\
\text { Thomas, } \\
\text { Gower, and } \\
\text { Michael (2014) }\end{array}$ & $\begin{array}{l}\text { Educational } \\
\text { innovation for } \\
\text { infection control in } \\
\text { Tanzania: bridging } \\
\text { the policy to practice } \\
\text { gap }\end{array}$ & $\begin{array}{l}\text { Tanzania, } \\
\text { Africa }\end{array}$ & $\begin{array}{l}\text { Original } \\
\text { article }\end{array}$ & $\begin{array}{l}\text { Present an } \\
\text { innovative } \\
\text { educational } \\
\text { framework to } \\
\text { bridge the gap } \\
\text { between globally } \\
\text { recognised IP\&C } \\
\text { policy, and realities } \\
\text { of practice in } \\
\text { Tanzania. }\end{array}$ \\
\hline
\end{tabular}

Efforts are made by resource-poor countries to guidelines however these are jeopardised by poor systems and processes.

Adapting follow recognised educational approaches to suit local participants does result in increased knowledge, however further research needs to be done.

\begin{tabular}{|c|c|c|c|c|c|c|c|c|}
\hline $\begin{array}{l}\text { Kong and Kong } \\
\text { (2013) }\end{array}$ & $\begin{array}{l}\text { A quality } \\
\text { improvement project } \\
\text { in a hospital in rural } \\
\text { Nepal - improving } \\
\text { infection control } \\
\text { practice using the } \\
\text { 'Plan, Do, Study, Act } \\
\text { (PDSA) cycle }\end{array}$ & Nepal & $\begin{array}{l}\text { Original } \\
\text { research }\end{array}$ & $\begin{array}{l}\text { Improve infection } \\
\text { control standards } \\
\text { in a rural district } \\
\text { hospital in Nepal } \\
\text { using the PDSA } \\
\text { cycle. }\end{array}$ & $\begin{array}{l}\text { Pre-post } \\
\text { intervention } \\
\text { observational } \\
\text { design }\end{array}$ & $\begin{array}{l}\text { Convenience } \\
\text { sample of } 22 \\
\text { doctors and } \\
\text { nurses }\end{array}$ & $\begin{array}{l}\text { Descriptive } \\
\text { statistics }\end{array}$ & $\begin{array}{l}\text { Improvement } \\
\text { in hand hygiene } \\
\text { amongst staff } \\
\text { is possible } \\
\text { through low-level } \\
\text { interventions. }\end{array}$ \\
\hline $\begin{array}{l}\text { Marjardi and } \\
\text { McLaws (2010) }\end{array}$ & $\begin{array}{l}\text { Rural Indonesian } \\
\text { health care workers' } \\
\text { constructs of } \\
\text { infection prevention } \\
\text { and control } \\
\text { knowledge }\end{array}$ & Indonesia & $\begin{array}{l}\text { Original } \\
\text { research }\end{array}$ & $\begin{array}{l}\text { Understand rural } \\
\text { Indonesian health } \\
\text { care workers } \\
\text { constructs of } \\
\text { knowledge } \\
\text { of infection } \\
\text { prevention and } \\
\text { control. }\end{array}$ & $\begin{array}{l}\text { Qualitative; } \\
\text { Direct } \\
\text { observation, } \\
\text { Individual and } \\
\text { focus group } \\
\text { discussion } \\
\text { and document } \\
\text { analysis }\end{array}$ & $\begin{array}{l}\text { Sample size } \\
\text { not declared. } \\
\text { Health care } \\
\text { workers from } \\
\text { ten rural } \\
\text { Indonesian } \\
\text { health care } \\
\text { facilities }\end{array}$ & $\begin{array}{l}\text { Grounded } \\
\text { theory }\end{array}$ & $\begin{array}{l}\text { Awareness of } \\
\text { HCAI was low, } \\
\text { protocols were } \\
\text { non-evidentiary, } \\
\text { therapy was driven } \\
\text { by organizational } \\
\text { culture, } \\
\text { empiricism and } \\
\text { patient demand } \\
\text { which all remained } \\
\text { undetected by } \\
\text { accreditation } \\
\text { systems. }\end{array}$ \\
\hline
\end{tabular}




\begin{tabular}{|c|c|c|c|c|c|c|c|c|}
\hline Meers (1988) & $\begin{array}{l}\text { Infection control in } \\
\text { developing countries }\end{array}$ & Global & Opinion & $\begin{array}{l}\text { Discuss problems } \\
\text { and solutions to } \\
\text { infection control } \\
\text { in developing } \\
\text { countries. }\end{array}$ & & & & $\begin{array}{l}\text { Problems arise } \\
\text { from difficulties } \\
\text { in communication } \\
\text { between } \\
\text { individuals, } \\
\text { variation in the } \\
\text { spectrum of } \\
\text { diseases and from } \\
\text { lack of money. } \\
\text { Nurses should } \\
\text { take take the } \\
\text { lead in applying } \\
\text { principles of IP\&C. }\end{array}$ \\
\hline $\begin{array}{l}\text { Mehtar, Marais, } \\
\text { and Aucamp } \\
\text { (2011) }\end{array}$ & $\begin{array}{l}\text { From policy to } \\
\text { practice - Education } \\
\text { in Infection } \\
\text { Prevention and } \\
\text { Control }\end{array}$ & $\begin{array}{l}\text { South } \\
\text { Africa }\end{array}$ & $\begin{array}{l}\text { Original } \\
\text { article }\end{array}$ & $\begin{array}{l}\text { Address methods } \\
\text { of teaching which } \\
\text { may be helpful } \\
\text { in imparting } \\
\text { evidenced-based } \\
\text { knowledge and } \\
\text { understanding } \\
\text { of the basic } \\
\text { principles of IP\&C } \\
\text { at different levels } \\
\text { of healthcare in } \\
\text { Southern Africa. }\end{array}$ & & & & $\begin{array}{l}\text { IP\&C should } \\
\text { be promoted } \\
\text { across all levels } \\
\text { of health care } \\
\text { workers but its } \\
\text { success depends } \\
\text { upon engaging } \\
\text { the public in the } \\
\text { process using } \\
\text { simple concepts, } \\
\text { local conditions } \\
\text { and disease } \\
\text { profiles. }\end{array}$ \\
\hline $\begin{array}{l}\text { Mugomeri } \\
\text { (2018) }\end{array}$ & $\begin{array}{l}\text { The efficacy } \\
\text { of infection } \\
\text { prevention and } \\
\text { control committee } \\
\text { in Lesotho: A } \\
\text { qualitative study }\end{array}$ & $\begin{array}{l}\text { Lesotho, } \\
\text { Southern } \\
\text { Africa }\end{array}$ & $\begin{array}{l}\text { Original } \\
\text { research }\end{array}$ & $\begin{array}{l}\text { Evaluate the } \\
\text { effectiveness of } \\
\text { infection control } \\
\text { committees in } \\
\text { the Southern } \\
\text { African country of } \\
\text { Lesotho. }\end{array}$ & $\begin{array}{l}\text { Qualitative } \\
\text { exploratory } \\
\text { study; open } \\
\text { interviews }\end{array}$ & $\begin{array}{l}\text { Purposive } \\
\text { sample, } 16 \text { key } \\
\text { informants }\end{array}$ & $\begin{array}{l}\text { Grounded } \\
\text { theory }\end{array}$ & $\begin{array}{l}\text { Infection control } \\
\text { committees were } \\
\text { ineffective for the } \\
\text { following reasons; } \\
\text { poor sense of } \\
\text { competence, } \\
\text { administrative } \\
\text { constraints, } \\
\text { inadequate } \\
\text { financial support, } \\
\text { role uncertainty } \\
\text { and negative staff } \\
\text { attitudes. }\end{array}$ \\
\hline
\end{tabular}




\begin{tabular}{lll}
\hline Pittet et al. & Infection control as a Global Review \\
(2008) & major World Health & \\
& Organization priority \\
& for developing \\
& countries
\end{tabular}

Review of the

implementation

of the first WHO

Global Patient

safety Challenge

'Clean care is safer

care' launched in

2004.
The first Global

Safety Patient

Safety Challenge is

offering a strategy

and tool to make

a difference

in infection

prevention

and patient

safety, however

surveillance data is

still lacking. Data

acquired from a

variety of settings

in a variety of

cultures and

systems will help

close the gap.

Only policies

adapted to local

conditions, owned

and practiced by

local experts and

workers are likely

to be sustainable.

Funding is the

key issue and

initiatives could

fail due to a lack

of sustainable

resources.

Infection control

activities are

limited by poor

infrastructure,

overcrowding,

inadequate

hygiene and

water supply and

poorly functioning

laboratory

services. There is

a need to reduce

the burden of

healthcare related

infections in

the tropics, and

set up effective

surveillance

programs. 


\begin{tabular}{|c|c|c|c|c|}
\hline Sobayo (1991) & $\begin{array}{l}\text { Nursing aspects of } \\
\text { infection control in } \\
\text { developing countries }\end{array}$ & Global & Opinion & $\begin{array}{l}\text { Discuss nursing } \\
\text { aspects of } \\
\text { infection control } \\
\text { in developing } \\
\text { countries. }\end{array}$ \\
\hline
\end{tabular}

\section{The problems \\ that developing \\ countries have \\ with nosocomial \\ infections are \\ ill-defined and \\ misunderstood \\ by developing \\ countries. \\ Solutions will only \\ evolve if there \\ is cooperation \\ between countries \\ and provision \\ of help where \\ appropriate.}

$\begin{array}{llll}\text { Zimmerman, } & \text { Success in the } & \text { Republic } & \text { Original } \\ \text { Yeatman, } & \text { South Pacific: a case } & \text { of Kiribati } & \text { research } \\ \text { Jones, and } & \text { study of successful } & & \\ \text { Murdoch } & \text { diffusion of an } & \\ \text { (2015) } & \text { infection prevention } & \\ & \text { and control program } & \end{array}$

Explore the role
of the Diffusion
of Innovation
framework in
adopting an IP\&C
program in a
low and middle
income country,
the Republic of
Kirabati.

Case study. Single case
Triangulation study
process using
multiple
sources of
evidence, both
qualitative and
quantitative.
Semi-
structured
interviews,
IP\&C
documentation,
program
evaluation and
healthcare
worker surveys.

$\begin{array}{ll}\begin{array}{l}\text { Thematic } \\ \text { analysis and }\end{array} & \text { The classic } \\ \text { descriptive } & \text { Innovation of } \\ \text { statistics } & \text { Organisations } \\ & \text { is a model that } \\ & \text { can explain the } \\ & \text { adoption of the } \\ \text { IP\&C program } \\ \text { in the Republic } \\ \text { of Kiribati, and } \\ \text { may be useful } \\ \text { as a framework } \\ \text { for other LMI } \\ \text { countries to } \\ \text { follow. }\end{array}$

Thematic The classic analysis and Diffusion of descriptive Innovations for Organisations is a model that can explain the adoption of the P\&C program in the Republic of Kiribati, and may be useful as a framework countries to

\section{Results}

The 16 articles included in the review consisted of three qualitative and one quantitative research design, four reviews, four opinion pieces, three original articles, and one discussion paper. Formal data collection methods consisted of interviews, surveys and observation, with the range of suggested practices including education activities for nursing staff and including consumer input to utilising a systems approach and restructuring hospital governance processes. Commonly a combination of practices was suggested to improve IP\&C success but most often these reflected modified western practices.
The opinion pieces, practice forum and discussion paper focussed more generally on the overarching problems associated with implementation of IP\&C and the change management needed to ensure a modicum of success.

Data quality varied across the 16 articles due mainly to the variety of documents included in the review. The four research papers had undergone peer review prior to publication but the opinion pieces reflect that they are an educated opinion and as such do not adhere to a rigorous study process. Despite this, all non-research papers were published in peer review journals. 
Review of data quality revealed that one study ${ }^{14}$ reported observation bias having influenced their findings. The same authors also described time constraints and non-representative sampling as limitations. Other studies cautioned against generalising results to a wider population due to the qualitative nature of the research methodology ${ }^{15,16}$ and one study ${ }^{17}$ identified that the sample size was relatively small which may have limited their results. Table II provides a summary of the articles included in this review.

The five over-arching themes identified across the sixteen publications in relation to the implementation of IP\&C programs in resource poor settings were: (1) education, (2) governance, (3) systems, (4) consumer involvement and (5) multi-modal approaches.

\section{Education}

The education of healthcare workers is essential to improve practices and healthcare worker education has a positive impact in reducing healthcareassociated infections. ${ }^{18}$ Despite this, education and training were only recognised in five publications as the primary driver in improving IP\&C in developing countries. Meers ${ }^{19}$ and Sobayo ${ }^{20}$ both identified that nurses were the key and should take the lead in improving IP\&C practices in developing countries, yet education about IP\&C in nursing curriculum was very limited. Sobayo ${ }^{20}$ suggested that in many developing countries nurses were more likely to introduce good infection control practices due to their concern for procedural standards, therefore should be appointed as infection control specialists and provided with appropriate education at approved institutions. The author did recognise that courses in developing countries were limited and expensive, and that more formal courses were required. Meers ${ }^{19}$ also recognised that education for nurses around IP\&C was limited and a lack of knowledge about emerging IP\&C practices by nursing tutors made it difficult to educate nursing students, and suggested low-key input at the nurse training level as a strategy for least developed countries. Despite arguing that education was the solution to improving IP\&C practices in developing countries, both authors recognised that a lack of material and financial resources, poor hospital infrastructure and the spectrum of diseases encountered all provided educational challenges.

In an attempt to understand what informed IP\&C knowledge in rural Indonesian health care workers (HCWs), Marjardi and McLaws ${ }^{15}$ found that despite the availability of IP\&C programs HCWs still had limited knowledge which resulted in unsafe clinical practice. A lack of control systems in the education and clinical setting allowed for non-evidenced-based teachings and therefore non-evidentiary practice. The study revealed that IP\&C knowledge was influenced by societal expectations, and HCW knowledge was influenced by their superiors, which was based on clinical experiences rather than evidence-based decisions. Nurses in rural Indonesia reported an unavailability of textbooks during their post-basic practice therefore relying on practical lessons to improve their knowledge. Again, this experiential learning was perceived to be of greater value than knowledge gained through formal education. The constructs of IP\&C knowledge that emerged from the study revealed that in the absence of HCAl surveillance results, laboratory, and diagnostic support, clinicians opted for observed and experiential practices. Marjardi and McLaws ${ }^{15}$ concluded that evidencedbased IP\&C education would be beneficial for HCWs in rural Indonesia and that this should be appropriate for low-resource health care facilities.

Mehtar, Marais and Aucamp ${ }^{21}$ agreed that changing ingrained practice through evidenced-based education is an important step in improving IP\&C practice in developing countries and that formal IP\&C courses in LMI countries were lacking. In South Africa, IP\&C education was mostly undertaken towards the end of or after medical students' undergraduate training, therefore IP\&C practices were behaviourally developed rather than being evidenced based. In describing a locally developed IP\&C educational structure the authors recognised that courses should be contextually appropriate and that local capacity building around IP\&C knowledge and teaching is important for courses to remain sustainable. 
Education programs tailored to the specific local context was a recurrent theme across the five papers. Jones, Whitfield, Thomas et al. ${ }^{5}$ described a program in Tanzania which abandoned traditional didactic teaching methods, and offered a blended approach using theoretical learning, group work, quizzes, roleplay, self-assessment and practical hand hygiene. Transcultural strategies such as use of local language by the educators, allowing time for traditional greetings, sharing of photos of family, and praise for current IP\&C strategies gained trust between the educators and the participants. Whilst there was no formal precourse, post-course assessment to ascertain learning, feedback via daily quizzes indicated an improvement in knowledge. What was also fundamental to success was having specific "change champions" to persist with the implementation of change. Not only did this prove highly important in building capacity but it provided an avenue for sustainability.

\section{Governance}

Poor governance of IP\&C leads to adverse patient outcomes. ${ }^{22}$ Monitoring of evidenced-based practice and guideline use, adherence to clinical pathways and models of care, and provision of cost-effective health service delivery are all ways in which effective governance of IP\&C can be measured. ${ }^{23}$ The implementation of effective guidelines underpinned by IP\&C programs requires the existence of, and leadership by, an IP\&C committee, which in turn requires organisational support, yet only one paper discusses governance in depth as the way forward. Despite the acknowledgement that most referral and district hospitals in developing countries had established multi-disciplinary IP\&C committees, only one paper described the effectiveness of IP\&C committees in implementing infection control programs. Mugomeri ${ }^{17}$ recognised that the strength of an infection control committee was indicated by their capacity to proactively deal with IP\&C issues, however the study revealed that hospital infection control committees were largely ineffective. The central emerging theme was that weak leadership and poor governance was the major barrier to effectiveness, however subthemes included a sense of incompetence, administrative and time constraints, role uncertainty, financial disincentives and negative staff attitudes.

\section{Systems}

Utilising a systems approach has been shown to improve IP\&C practice in developed countries. Systems such as continuous quality improvement (CQI) increase the effectiveness and efficiency of care, and can optimise systems of care while utilising existing resources; ${ }^{24}$ however, publications that describe the experience that developing countries have in implementing CQI models or frameworks to improve IP\&C practices are limited. ${ }^{24}$ Three papers described the adaptation of western-based systems as models to improve IP\&C. The 'Plan, Do, Study, Act' (PDSA) cycle as a CQI model for improving IP\&C practices in developing countries is discussed in two papers. Huskins, Soule, O'Boyle et al. ${ }^{24}$ described how the principles that underpin the PDSA cycle, which have been well tested as a healthcare CQI model in developed countries, were applied to a developing country. The authors took into consideration the lower resource setting and suggested possible changes from the western-based model at each step of the cycle.

A more successful translation of the PDSA cycle to a developing country is described by Kong and Kong ${ }^{14}$ who explained a simple yet effective method of improving awareness and practice of hand hygiene. At the 'Do' stage of the cycle, localised and simple strategies were implemented and included educational presentations, simple diagrammatic posters, increasing the availability of alcohol-based hand rub (ABHR) and the introduction of "infection control champions", all of which were found to be successful. ${ }^{14}$ The authors recognised the limitations of their study; encouragingly, given the known biases, the authors found the improvement in hand hygiene episodes rose from $13.4 \%$ to $48.6 \%$.

The diffusion of innovation framework has also been shown to be successful in the adoption of a comprehensive IP\&C program in a low-middle income country. Diffusion of innovation theory describes "the process by which an innovation is communicated through certain channels over time among members of a social system". ${ }^{8}$ Diffusion of innovation theory emerged from agriculture and education but is now widely used in health sciences. ${ }^{25}$ Zimmerman, Yeatman, Jones et al. ${ }^{16}$ demonstrated the model could be successfully used to explain the adoption of an IP\&C 
program in a developing country, and illustrated how the end users with little involvement from external agencies could implement an IP\&C program.

\section{Consumer participation}

Health systems should be responsive to consumers' expectations and needs, which means health services should actively seek out opportunities to improve their understanding and awareness of consumers' views. ${ }^{26}$ In the context of a developing country where consumers' culture, and spiritual and religious beliefs are central and vastly different from that of a developed country, considering these when improving healthcare practices is vital. In spite of this acknowledgement, only three of the 16 papers specifically commented on the importance of patient involvement, culture and religion when improving IP\&C practices. ${ }^{27-29}$ Bardossy, Zervos and Zervos ${ }^{28}$ recognised that it was important to consider that behavioural, transcultural and religious factors may affect outcomes when planning IP\&C interventions. Taking into consideration cultural dimensions such as power imbalance in the workplace had shown successful improvement when implementing IP\&C strategies in some Anglo-Saxon and Scandinavian countries, however the authors acknowledged that the lack of information around cultural dimensions in developing countries made it difficult to translate these practices.

The importance of culture and religion is also recognised by Allegranzi, Memish, Donaldson et al. ${ }^{27}$ particularly when implementing hand hygiene measures. Poor hospital infrastructure, such as a lack of sinks and running water, means that simple interventions such as hand hygiene are difficult to implement in developing countries and while Pittet, Allegranzi, Storr et al. ${ }^{29}$ suggested the use of $A B H R$ as a solution, encouraging the practice of hand hygiene and the use of $A B H R$ is not culturally sensitive in some settings. The role that religion and culture have on influencing hand hygiene practices of healthcare workers was profoundly influenced by culture and religion. ${ }^{27}$ Many hand hygiene practices were associated with daily prayer rituals and not necessarily for hygiene requirements. Alcohol prohibition in religions such as Buddhism, Islam and Sikhism prevented the use of ABHR by healthcare workers, and hand gestures such as the designation of a 'clean' hand and an 'unclean' hand, and the specific cultural meaning of folding hands as a form of greeting influenced how health care workers perceived hand hygiene education messages. ${ }^{27}$ Consulting local religious authorities played an important role when developing local programs around the use of $A B H R$, and developing culturally appropriate hand hygiene promotional materials in collaboration with health care workers was suggested. The recognition of patient involvement, and religious and cultural issues when developing IP\&C programs was discussed as a 'lesson learned' by Pittet, Allegranzi, Storr et al. ${ }^{29}$ when piloting global IP\&C recommendations.

\section{Multi-modal approaches}

Four of the 16 publications discussed that the successful implementation of any infection control program required a multi-modal approach. All authors agreed that designated staff responsible for infection control activities who were appropriately trained was essential to success. ${ }^{6,30-32}$ Provision of training needed to be simple and practical ${ }^{30,31}$ incorporated into other training activities two or three days very year and with uncomplicated textual materials. ${ }^{31}$ Provision of a short list of 'do's and don'ts' was suggested as being more appropriate and liable to lead to success than using complicated infection control manuals. ${ }^{6}$

While the authors recognised that hospitals in developing countries are not well equipped with isolation facilities and that positive and negative pressure rooms are rarely available, ${ }^{6}$ the provision of infrastructure that allowed for the isolation of patients with communicable or multi-resistant infections in either single rooms, or through cohorting, was a useful, simple and no-cost IP\&C measure. $6,30,32$ Appropriate antibiotic use was seen as challenging in developing countries due to increased numbers of unqualified providers, self-prescribed over the counter purchases, poor quality control in drug production, ${ }^{6}$ a lack of susceptibility testing facilities ${ }^{31}$ and practices leading to disproportionately high rates of multi-resistant organisms. The development of local antibiotic use programs which included a six monthly rotation of available prescription-free antibiotics was recommended to address the high antibiotic resistance rates ${ }^{6}$ coupled with improving laboratory 
facilities, improved susceptibility testing ${ }^{32}$ and sample sensitivity testing to detect alterations in resistance patterns ${ }^{31}$ were suggested as important measures to improve IP\&C.

The improvement in hand hygiene practices was recognised as an important strategy in three of the four papers despite the acknowledgement of poor water supplies and a lack of resources. ${ }^{6,30,32}$ Promoting good hand hygiene practice and the provision of soap and water was suggested despite evidence that compliance rates using the same method in some European hospitals was generally low. ${ }^{6,30,32}$ The use of ABHR instead of soap was proposed as it negated the need for installation of extra taps and basins, however the authors admitted the lack of availability of $A B H R$ was challenging. Local innovations such as supplying $A B H R$ in appropriately improvised plastic dispensers was an inexpensive way of improving hand hygiene practices 6 but again this was contraindicated in a number of countries due to religious and cultural restrictions around the use of alcohol.

All papers identified administration environments as a potential problem to successful implementation of IP\&C programs and practices. ${ }^{6,30-32}$ Unclear accountability and responsibility of administrators and managers of healthcare facilities often resulted in stalled change processes with service delivery. ElNageh $^{31}$ acknowledged that despite the similarities between health facilities in relation to services offered and number of beds, the differences between them made generalised infection control interventions difficult to apply. Although the authors advocated for simple multimodal measures such as a surveillance system which reflected the characteristics of the hospital in combination with an infection control committee which could implement programs suiting the size of the facility, and minimal, time saving education programs, the uptake and sustainability of the approach by health systems in many developing countries was poor.

Although the uptake of El-Nageh's ${ }^{31}$ three tier IP\&C program was poor, the essence of the design meant it could be applied to meet the essential needs of small facilities through to facilities which provided more complex care. Similarly, Damani ${ }^{30}$ agreed that to reduce $\mathrm{HCAl}$ in developing countries, minimal, cost-effective measures that suit the local needs and circumstances must be applied. Damani highlighted that by monitoring hospital IP\&C performance, changes in IP\&C practice could be made. Importantly, only basic surveillance which identified the key issues or concerns relevant to the facility should be undertaken. Although Damani's suggestion mimics western IP\&C practice, for resource limited settings simple process surveillance is not only cost-effective but identifies immediately unsafe IP\&C activities, and feedback to healthcare workers to improve practice can occur without delay.

\section{Discussion}

There is much rhetoric in the literature around why and how IP\&C practices in developing countries should be improved, but there is a paucity of research publications describing any comprehensive and sustainable solutions. There were individually tailored components of programs mentioned throughout all of the literature; however, there was little depth to most of these discussions. The colonialist undercurrent that pervaded much of the literature indicated that while the need for local solutions is recognised, there is very little to prove that this is happening.

Since the release of the SENIC project in the late 1970 's, education has been recognised as pivotal in improving practice in developing countries, and both Meers ${ }^{19}$ and Sobayo ${ }^{20}$ recognised that nurses could undertake this role. Given that at the time of these publications the SENIC project was only ten years old, barriers such as a lack of formal courses, unavailability of textbooks and overall ignorance of this emerging specialty made it difficult for nurses to be educators. Almost 20 years on and the same challenges facing educating healthcare workers in developing countries continue to exist. In addition to the known barriers, in many developing countries there is evidence to suggest that community expectations depart from recognised programs which encourages non-evidentiary practice, and the continuation of ingrained behaviours over any formalised IP\&C training. . $^{15,21}$

The scientific and bio-medical principles that underpin IP\&C programs world-wide are the same, and for developing countries improving patient 
outcomes requires the adoption of scientific based IP\&C standards and programs, strong leadership and organisational support. ${ }^{17}$ The literal adoption of programs developed by western countries into a resource poor setting has been limited in their success, and may be improved through an integrative approach between western-based and locally developed standards. ${ }^{5,33}$ Education of healthcare workers and an understanding of what informs peoples practice have been shown to reduce HCAI rates; however, for this to occur in developing countries education programs need to be developed towards specific healthcare contexts. Using non-didactic, alternative teaching strategies and incorporating informed transcultural approaches not only help gain trust between educators and participants but also enable learning to occur in a culturally sensitive way. ${ }^{5}$

Continuous quality improvement is well recognised and actively practiced by healthcare organisations in developed countries; however, this is not the experience in developing countries. Resource limitations mean that the adoption of CQI activities in developing countries is absent or varied, yet when effectively applied, CQI models do have the ability to optimise care while utilising limited available resources. The PDSA cycle is one well-tested CQI model which has been theoretically applied to demonstrate the decrease in surgical site infections in a larger hospital in a developing country, ${ }^{24}$ while in a smaller hospital, the PDSA cycle was effectively used to improve hand hygiene rates by adapting western concepts to the local setting. ${ }^{14}$ Understanding the social connectedness and communication channels that occur during the natural implementation of an IP\&C program in a developing country can motivate hospital staff to independently take ownership of the process. $^{16}$

It has been acknowledged frequently in the literature that collaborating with community in adapting and developing programs and involvement in implementing IP\&C programs in developing countries is pivotal, yet there were few realistic examples. Success has been demonstrated through locally developed educational activities, locally made hand hygiene products, surveillance activities that target locally relevant diseases, and adapting CQI processes to suit available resources.

Cultural information around healthcare implementation practices was scarce. The influence that culture, religion and spiritual beliefs have on patient and healthcare worker perceptions of causation and transmission of disease, and the impact these have on IP\&C program implementation, was missing in much of the literature. The health systems approachtoIP\&Cisbased onthegerm theoryofdisease transmission, yet it is only one of the explanations for disease transmission in many locations. Religion and culture play an important role in the health of people in many countries, so to adopt IP\&C practices, such as using $A B H R$ for hygiene purposes, may be detrimental to the health of populations due to breaking religious rules around alcohol use. So, while healthcare providers may believe in the germ theory of disease, other influential beliefs play a pivotal role in healthcare practices in some countries.

The differences in culture between countries mean that a blanket approach will be inneffective. ${ }^{28}$ Building IP\&C capacity through partnerships is a powerful strategy to improve IP\&C in developing countries. For this to be successful and sustainable, healthcare facilities must be not be seen as passive recipients, but as active participants. When international IP\&C programs ignore the social, economic and cultural determinants of health, the implementation of these programs will ultimately fail. ${ }^{28}$ The importance of capacity building at an international level and the involvement of ministries of health and other health institutions when developing suitable programs are important because when people transcend borders, so do infections. ${ }^{28}$

\section{Implications for practice}

Understanding how healthcare workers from different cultural, religious and spiritual backgrounds view causation of infection and infection transmission, and identifying the issues around established IP\&C practice as understood by healthcare workers, are areas needing further research. Only then can culturally relevant and sustainable IP\&C practices be implemented to improve patient outcomes. There is 
potential for experienced IP\&C practitioners to work with healthcare providers in developing countries to enable them to come up with their own solutions to IP\&C issues. Programs that are community owned and developed, and are culturally inclusive, can be enriched over time. There have been some successes in implementing segments of IP\&C programs using locally adapted approaches and collaborating with healthcare organisations, however participatory research approaches must be considered to identify the meaning of IP\&C as perceived by the people that deliver healthcare in developing countries.

\section{Limitations}

Searching for literature written in English language only was a limitation of this review. Given the aim of this review it is possible that studies, particularly by authors from developing countries, will have been missed. While the terms "developing country" and "limited resource" were entered into the databases, other terms such as "lower-middle income" were often used as a synonym within the literature, a term that was not used in the initial search.

\section{Conclusion}

Improvement in IP\&C practices in developing countries is complex and while programs exist, barriers and challenges mean that a one-size-fits all approach does not work. What may be beneficial is a locally adapted, well-tested framework to support program development, which includes for sustainability, a bottom-up program for capacity building of healthcare workers. Embedded throughout the program to encourage success, must also be the principles of good governance and a clear regard for culture, language and religious or spiritual beliefs.

\section{References}

1. Alp E, Leblebicioglu H, Doganay M, Voss A. Infection control practice in countries with limited resources. Annals of Clinical Microbiology and Antimicrobials 2011; 10: 36 . https://doi. org/10.1186/1476-0711-10-36

2. United Nations. World economic situation and prospects 2014. 2014; Available from: https://www.un.org/development/ desa/dpad/document_gem/global-economic-monitoringunit/world-economic-situation-and-prospects-wesp-report/

3. United Nations. LDC identification criteria \& indicators. 2018; Available from: https://www.un.org/development/desa/dpad/ least-developed-country-category/ldc-criteria.html
4. Gupta I, Guin P. Communicable diseases in the South-East Asia Region of the World Health Organization: towards a more effective response. Bulletin of the World Health Organization 2010; 88: 199-205. https://doi.org/10.2471/BLT.09.065540

5. Jones M, Whitfield A, Thomas S, Gower S, Michael R. Educational innovation for infection control in Tanzania: bridging the policy to practice gap. Journal of Infection Prevention 2014; 15(3): 94-98. https://doi. org/10.1177/1757177413516525

6. Raza MW, Kazi BM, Mustafa M, Gould FK. Developing countries have their own characteristic problems with infection control. Journal of Hospital Infection 2004; 57(4): 294-343. https://doi.org/10.1016/j.jhin.2004.03.019

7. International Federation of Infection Control, Basic Concepts English Version, in Organisational Structure. 2016, International Federation of Infection Control.

8. Zimmerman PA, Yeatman H, Jones M. Frameworks to assist adoption of infection prevention and control programs. Does the literature exist? Healthcare Infection 2011; 16(4): 129-134. https://doi.org/10.1071/HI11021

9. Hancart-Petitet P, Dumas C, Faurand-Tournaire A-L, Desclaux A, Vong S. Social and cultural dimensions of hygiene in Cambodian health care facilities. BMC Public Health 2011; 11(1): 83. https://doi.org/10.1186/1471-2458-11-83

10. Nagy S, Mills J, Waters D, Birks M. Using research in healthcare practice. Sydney: Lippincott Williams \& Wilkins, 2010.

11. Huskins, Soule B. Infection control in countries with limited resources. Current Opinion in Infectious Diseases 1998; 11(4): 449-455. https://doi.org/10.1097/00001432-19980800000010

12. MoherD,LiberatiA, TetzlaffJ,AltmanDG. Preferred Reporting Items for Systematic Reviews and Meta-Analyses: The PRISMA Statement. Journal of Clinical Epidemiology 2009; 62: 1006-1012. https://doi.org/10.1016/j.jclinepi.2009.06.005

13. Critical Appraisal Skills Programme. CASP checklists. 2018; Available from: https://casp-uk.net/casp-tools-checklists/

14. Kong K, Kong S. A quality improvement project in a hospital in rural Nepal - improving infection control practice using the 'Plan, Do, Study, Act' (PDSA) cycle. International Journal of Infection Control 2013; 9(3): https://doi.org/10.3396/IJIC. v9i3.025.13

15. Marjardi B, McLaws M-L. Rural Indonesian health care workers' constructs of infection prevention and control knowledge. American Journal of Infection Control 2010; 38(5): 399-403. https://doi.org/10.1016/j.ajic.2009.11.010

16. Zimmerman PA, Yeatman $\mathrm{H}$, Jones M, Murdoch $\mathrm{H}$. Success in the South Pacific: a case study of successful diffusion of an infection prevention and control program. Healthcare Infection 2015; 20(2): 54-61. https://doi.org/10.1071/HI14036

17. Mugomeri E. The efficacy of infection prevention and control committees in Lesotho: A qualitative study. American Journal of Infection Control 2018; https://doi.org/10.1016/j. ajic.2017.11.028

18. Mathai E, Allegranzi B, Seto WH, et al. Educating healthcare workers to optimal hand hygiene practices: addressing the need. Infection, 2010; 38(5): 349-356. https://doi. org/10.1007/s15010-010-0047-7 
19. Meers PD. Infection control in developing countries. The Journal of hospital infection 1988; 11 Suppl A: 406-410. https:// doi.org/10.1016/0195-6701(88)90219-8

20. Sobayo El. Nursing aspects of infection control in developing countries. The Journal of Hospital Infection 1991; 18 Suppl A: 388-391. https://doi.org/10.1016/0195-6701(91)90046-B

21. Mehtar S, Marais F, Aucamp M. From policy to practice education in infection prevention and control. International Journal of Infection Control 2011; 7(2):https://doi/org/10.3396/ ijic.V7i2.016.11

22. National Health and Medical Research Council. Australian Guidelines for the Prevention and Control of Infection in Healthcare. 2010; Available from: https://nhmrc.gov.au/ about-us/publications/australian-guidelines-prevention-andcontrol-infection-healthcare-2010

23. CRANAplus, A clinical governance guide for remote and isolated health services in Australia. 2013, Alice Springs: CRANAplus.

24. Huskins, Soule BM, O’Boyle C, Gulácsi L, O'Rourke EJ, Goldmann DA. Hospital Infection prevention and control: a model for improving the quality of hospital care in low- and middle-income countries. Infection Control and Hospital Epidemiology 1998; 19(2): 125-135. https://doi. org/10.2307/30142003

25. Dearing J, Cox J. Diffusion of innovations theory, principles, and practice. Health Affairs 2018; 37: 183-190. https://doi. org/10.1377/hlthaff.2017.1104

26. Australian Commission on Safety and Quality in Health Care. Health Literacy. 2019; Available from: https://www. safetyandquality.gov.au/our-work/patient-and-consumercentred-care/health-literacy/
27. Allegranzi B, Memish Z, Donaldson L, Pittet D. Religion and culture: Potential undercurrents influencing hand hygiene promotion in health care. American Journal of Infection Control 2009; 37(1): 28-34. https://doi.org/10.1016/j. ajic.2008.01.014

28. Bardossy AC, Zervos J, Zervos M. Preventing hospital acquired infections in low-income and middle-income countries: Impact, gaps and opportunities. Infectious Diseases Clinics of North America 2016; 30: 805-818. https://doi.org/10.1016/j. idc.2016.04.006

29. Pittet D, Allegranzi B, Storr J, et al. Infection control as a major World Health Organization priority for developing countries. Journal of Hospital Infection 2008; 68(4): 285-292. http:// dx.doi.org/10.1016/j.jhin.2007.12.013

30. Damani N. Simple measures save lives: an approach to infection control in countries with limited resources. The Journal of hospital infection 2007; 65 Suppl 2(2): 151-154. https://doi.org/10.1016/S0195-6701(07)60034-6

31. El-Nageh MM. How to combat nosocomial infection in developing countries. World Health Forum 1995; 16(3): 262266.

32. Shears P. Poverty and infection in the developing world: Healthcare-related infections and infection control in the tropics. Journal of Hospital Infection 2007; 67(3): 217-224. https://doi.org/10.1016/j.jhin.2007.08.016

33. Zimmerman PA. Help or hindrance? Is current infection control advice applicable in low- and middle-income countries? A review of the literature. Am J Infect Control 2007; 35(8): 494-500. https://doi.org/10.1016/j.ajic.2007.07.003 